\title{
Euthymia: a neglected aspect of trait depression and its role in predicting subjective well-being
}

\author{
Wactaw Bąk (DD) A,B,C,D,E,F, Matgorzata Eysiak (DD ${ }^{A, B, D, E, F}$ \\ The John Paul II Catholic University of Lublin, Lublin, Poland
}

\section{BACKGROUND}

Besides its relationship with clinical depression, depressiveness may be conceptualized as a personality trait that includes dysthymia (negative emotional experiences) and euthymia (positive emotional experiences). Euthymia, when reverse scored, makes the construct of trait depression more sensitive to milder levels of depressiveness observed in non-clinical samples. We hypothesised that euthymia is a more important predictor of subjective wellbeing than dysthymia and this effect is retained when basic positive and negative affect are controlled.

\section{PARTICIPANTS AND PROCEDURE}

Participants were 213 adults (56\% females) aged between 19 and $61(M=35.85, S D=11.30)$. They completed selfreport measures of: (a) euthymia and dysthymia as two facets of trait depression, (b) satisfaction with life, and (c) positive and negative affect.

\section{RESULTS}

The results showed that positive affect and euthymia contributed independently to explaining the variance of satisfaction with life, but the predictive role of euthymia was stronger. In contrast, dysthymia turned out not to predict satisfaction with life when controlled for basic affect and euthymia.

\section{CONCLUSIONS}

Theoretical implications of the results are discussed with their applications for counselling and clinical practice. We point to the need of monitoring the level of euthymia in the prevention programmes against depression, which is in line with the well-established role of positive interventions in psychotherapy and counselling.

KEY WORDS

depression; euthymia; dysthymia; well-being; satisfaction with life

Corresponding Author - Wacław Bąk, Ph.D., Institute of Psychology, The John Paul II Catholic University of Lublin,

Al. Racławickie 14, 20-950 Lublin, Poland, e-mail: waclaw.bak@kul.pl

AUthors' CONTRIBUtion - A: Study design - B: Data collection · C: Statistical analysis · D: Data interpretation .

E: Manuscript preparation · F: Literature search · G: Funds collection

TO CITE THIS ARTICLE - Bąk, W., \& Łysiak, M. (2021). Euthymia: a neglected aspect of trait depression and its role

in predicting subjective well-being. Current Issues in Personality Psychology, 9(4), 281-288.

RECEIVED 30.10.2020 · REVIEWED 30.11.2020 • ACCEPTED 01.02.2021 • PUBLISHED 10.04.2021 


\section{BACKGROUND}

The aim of the present study was to explore in more detail the relationship between subjective well-being (SWB) and depression. According to Diener's wellrecognized (1984) definition, SWB involves high positive affect, low negative affect and high satisfaction with life, which implicitly suggests an inverse relationship with depression. Some authors have even conceived depression as the loss of subjective well-being (Gargiulo \& Stokes, 2009). Many researchers have found that the lower subjective well-being is, the higher is the severity of depression (Goldberg \& Harrow, 2005; Wood \& Joseph, 2010). This effect is consistent between age groups and cultures (Carandang et al., 2019; Derdikman-Eiron et al., 2011; Rao et al., 2017; Van Beveren et al., 2018).

This seemingly clear issue becomes more complex when: (a) depression is conceived as a personality dimension (depressiveness) rather than in clinical terms and when (b) subcomponents of this construct are considered. Such conceptualization of depressiveness draws on Cattell and Scheier's (1960) distinction between state and trait aspects of emotional experience as well as on Spielberger's (2006, p. 301) theorizing that "individual differences in anxiety, anger and depression as personality traits can be evaluated in terms of frequency that these emotions are experienced". The present paper is focused on trait depression, i.e. depression conceived as a personality dimension rather than a clinical condition.

Given that "traits are presumed to be relatively enduring psychological characteristics that influence people's thoughts, feelings and behaviours" (Nezlek, 2007 , p. 791), trait depression is defined as a personality disposition to experience depressive emotions across contexts and situations. In terms of the Five Factor Model of personality, trait depression refers to the depression facet of neuroticism, which is defined as "the disposition to experience sadness, hopelessness, and loneliness" (McCrae \& Costa, 2003, p. 48). Depressiveness here is conceived as a dispositional form of the emotional state of sorrow, and high levels of this trait are related to feelings of guilt and diminished self-worth.

Most conceptualizations of depression, regardless of whether they refer to a clinical condition or a personality trait, are focused on its dysthymic aspect, which refers to experiencing negative emotional states and/or negative symptoms. In contrast, Spielberger et al. (2003) and Spielberger and Reheiser (2009) argued that trait depression should be described in terms of two interrelated but distinct facets called dysthymia and euthymia. They refer to separate - negative vs positive - aspects of affectivity associated with depression. Dysthymia is a depression-presence factor, while euthymia is a depression-absence factor. Whereas dysthymia is strongly emphasized in the depression literature, the euthymia aspect captures a neglected facet of depressiveness. It refers to depression in an indirect way, by pointing to deficits in positive emotions. This emphasis on positive experiences is clearly reflected in the etymology of the term "euthymia". It comes from the combination of the Greek words "eu", which means "well", and "thymeo", meaning "soul, emotion", or from the verb "euthymeo", which means "I am happy" (Fava \& Bech, 2016, p. 1).

The distinction between dysthymia and euthymia is particularly relevant for studying depressiveness in non-clinical samples, because it broadens the spectrum of depression-related experiences. While dysthymia refers to negative emotional experiences typical for higher levels of depression including its clinical symptoms, the reversed euthymia factor is more sensitive to milder levels of depressiveness (Spielberger et al., 2003). This two-facet conceptualisation of depression is thus particularly useful as a theoretical framework for a more detailed analysis of the relationship between depression and subjective well-being in the general population (as contrasted with clinically depressed individuals).

We hypothesised that for the general population the euthymia facet of depression is a more important predictor of SWB than the dysthymia facet. Among the subcomponents of SWB hedonic well-being is usually defined in terms of experiencing positive affective states or subjective happiness (Diener, 1984; Sin \& Lyubomirsky, 2009; Spinhoven et al., 2015). Similarly, hedonic balance defined as perceived experience of positive affect relative to negative affect (Allen et al., 2016; Stillmaker \& Kasser, 2013) is considered to be a strong indicator of the emotional component of well-being (Caprara \& Steca, 2006; Schimmack, 2003). Likewise, the preponderance of positive over negative affect along with the focus on an overall affective appraisal of life is the key element of happiness (Ryan \& Deci, 2001; Sin \& Lyubomirsky, 2009). Happy individuals with a positive view of life are characterized by a higher level of life satisfaction and psychological well-being including purpose of life and self-acceptance. This suggests that it is the presence of positive psychological resources, rather that the absence of negative affect, which protects against the occurrence of depressive symptoms (Xu et al., 2015). We thus expected that for the non-clinical population euthymia is a more important predictor of SWB that dysthymia.

One may wonder whether this relatively lessknown dysthymia-euthymia distinction is not redundant with the well-known distinction between positive and negative affect (PA, NA; Watson \& Tellegen, 1985). Thus, we controlled for the basic levels of PA and NA. We expected that the predictive role of euthymia over dysthymia for SWB would be retained when PA and NA were taken into consideration. 


\section{PARTICIPANTS AND PROCEDURE}

\section{PARTICIPANTS}

A total of 213 community dwelling adults (females $n=119,56 \%)$, aged $19-61\left(M_{\text {age }}=35.85, S D=11.30\right)$ participated in the study. All participants were informed about the aim and procedure of the study. Those who gave their agreement to participate completed self-report measures (as listed below) in the paper-pencil format. They did not receive compensation for their participation.

\section{MEASURES}

Trait depression. In line with the focus of this study on trait depression, the two components of depressiveness, i.e. trait dysthymia and trait euthymia, were measured by the trait scales from the State-Trait Depression Scales (STDS; Krohne et al., 2002; Spielberger et al., 2003) in the Polish adaptation by Bąk and Oleś (2005) (see also Bąk \& Łysiak, 2018). The development of the STDS was guided by the need for more efficient measures of different degrees of state and trait depression in non-clinical samples. The existing measures of depression, widely used in psychological research (e.g. Beck Depression Inventory), are effective in screening the general population for people with clinical depression. However, they are unable to differentiate between milder levels of depressiveness within non-clinical samples (Krohne et al., 2002). The STDS was designed to do so by including both depression-present (dysthymia) and depression-absent (euthymia) items. This drew on the concept of item-intensity specificity, stating that individual items are more effective in measuring a given construct at some levels of underlying theoretical dimension than at other levels (Spielberger et al., 2003). With reference to trait depression "the concept of item-intensity specificity calls attention to the fact that depression-absent items (...) when reverse scored, are more sensitive for assessing lower levels of depression, whereas depression-present items (...) are more effective measures of higher levels of depression” (Spielberger et al., 2003, p. 230).

The STDS trait depression scale is composed of 10 dysthymia items (e.g. "I feel miserable", "I feel low") and 10 euthymia items (e.g. "I feel strong", "I feel happy"). Participants responded to each item using a 4-point frequency scale ranging from 1 (almost never) to 4 (almost always) to indicate how they generally feel. The reliability of dysthymia and euthymia subscales for the current sample were $\alpha=.91,95 \%$ CI [.89, $.93]$ and $\alpha=.89,95 \%$ CI [.87, .91], respectively.

Subjective well-being. Subjective well-being (SWB) was operationalized in terms of satisfaction with life measured by the Satisfaction with Life Scale (SWLS; Diener et al., 1985) in the Polish adaptation by Juczyński (2012). The SWLS is a 5-item scale designed to measure global cognitive judgments of one's satisfaction with life. Participants indicate how much they agree with each item (e.g. "In most ways my life is close to my ideal") using a 7-point scale ranging from 1 (strongly disagree) to 7 (strongly agree). The reliability of the SWLS score for the current sample was $\alpha=.80,95 \%$ CI $[.75, .84]$.

Positive and negative affect. The basic affect was measured with the Positive and Negative Affect Schedule (PANAS; Watson et al., 1988), which in the Polish adaptation consists of 20 or 30 items, depending of the version of PANAS (Brzozowski, 2010). We used a longer version composed of 15 positive affect items (e.g. strong, active) and 15 negative affect items (e.g. distressed, upset), to which participants respond on a 5-point scale ranging from 1 (very slightly or not at all) to 5 (extremely). The reliability of PA and NA subscales was $\alpha=.86,95 \% \mathrm{CI}[.84, .89]$ and $\alpha=.78$, $95 \%$ CI $[.74, .82]$ respectively.

\section{RESULTS}

Table 1 presents means, standard deviations, and reliability coefficients for all scales included in the study as well as intercorrelations between the variables. To test the hypothesis that euthymia predominates over

\section{Table 1}

Descriptive statistics, bivariate correlations, and reliability coefficients

\begin{tabular}{lcccccccc}
\hline Variables & $M$ & $95 \% \mathrm{Cl}$ & $S D$ & 1 & 2 & 3 & 4 & 5 \\
\hline 1. Dysthymia & 1.75 & {$[1.67,1.82]$} & 0.58 & $(.91)$ & & & & \\
2. Euthymia & 2.90 & {$[2.82,2.98]$} & 0.61 & -.65 & $(.89)$ & & & \\
3. Positive affect & 3.18 & {$[3.09,3.27]$} & 0.66 & -.55 & .54 & $(.86)$ & & \\
4. Negative affect & 2.04 & {$[1.92,2.15]$} & 0.83 & .42 & -.45 & -.25 & $(.78)$ \\
5. Satisfaction with life & 4.21 & {$[4.06,4.37]$} & 1.13 & -.39 & .47 & .42 & -.28 & $(.80)$ \\
\hline Note. All correlations are significant at $p<.001$ Cronbach's alphas are presented in parentheses along the diagonal.
\end{tabular}


dysthymia in predicting satisfaction with life and that this effect is retained when positive and negative affect are controlled, we conducted a hierarchical regression analysis with SWLS as the dependent variable. Checking for collinearity of predictors the appropriate diagnostics showed that the assumptions were met (VIF ranged between 1.07 and 2.03; tolerance ranged between .49 and .94). We entered the predictor variables in three blocks (steps) to control for their independent role in predicting the outcome variable. NA and PA were entered as the first block, followed by dysthymia in the second step and finally euthymia in the third step (see Table 2).

First, the results showed that both PA and NA are significant predictors of SWLS, though the predictive role of positive affect was twice as strong as the role of negative affect. Those basic temperamental aspects of affect accounted jointly for $21 \%$ of variance of satisfaction with life. Entering the dysthymia aspect of trait depression at the second step added $2 \%$ of explained variance of SWLS. Dysthymia turned out to be a significant predictor of SWLS independently of PA. Moreover, when dysthymia was entered in the regression model NA was no longer a significant predictor of SWLS.

Entering the euthymia aspect of trait depression in the third step of the regression model added an- other $4 \%$ of variance explained by the predictors and showed that euthymia is the most important predictor of SWLS. The predictive role of NA remained statistically non-significant and additionally dysthymia lost its predictive power for euthymia. PA remained a significant predictor, though its role was weaker compared to both the first and the second steps. It was also noticeably weaker than the predictive role of euthymia.

For the sake of parsimony of the model we finally ran the second regression from which NA and dysthymia were excluded, since they turned out to be statistically non-significant predictors. The results reported in Table 3 showed that euthymia and positive affect contribute independently to predicting SWLS. The higher the levels of euthymia and PA are, the higher is satisfaction with life. However, the predictive role of euthymia is stronger compared to PA. The second model, which includes only two predictors (euthymia aspect of depressiveness and positive affect), can be regarded as a more parsimonious model compared to the original four-predictor model. The simpler model was similarly effective in predicting SWLS ( $R^{2}$ values for both models were equal), and it turned out to be a better model in terms of both the Akaike information criterion and the Bayesian information criterion (see AICs and BICs in Tables 2 and 3).

Table 2

Hierarchical multiple regression analysis predicting satisfaction with life (SWLS) - model 1: four predictors

\begin{tabular}{|c|c|c|c|c|c|c|c|}
\hline Predictor variable & $\Delta R^{2}$ & $\mathrm{AIC}$ & $\mathrm{BIC}$ & $B[95 \% \mathrm{Cl}]$ & $\beta$ & $t$ & $p$ \\
\hline Step 1 & $.21^{* * *}$ & 8.12 & 18.21 & & & & \\
\hline Constant & & & & $2.68[1.83,3.53]$ & & & \\
\hline Positive affect & & & & $0.64[0.43,0.85]$ & .38 & 5.93 & $<.001$ \\
\hline Negative affect & & & & $-0.25[-0.42,-0.08]$ & -.18 & -2.86 & .005 \\
\hline Step 2 & $.02^{*}$ & 5.50 & 18.95 & & & & \\
\hline Constant & & & & $3.54[2.38,4.69]$ & & & \\
\hline Positive affect & & & & $0.51[0.26,0.75]$ & .30 & 4.07 & $<.001$ \\
\hline Negative affect & & & & $-0.18[-0.36,0.01]$ & -.13 & -1.95 & .053 \\
\hline Dysthymia & & & & $-0.33[-0.63,-0.03]$ & -.17 & -2.14 & .033 \\
\hline Step 3 & $.04^{* * *}$ & -4.08 & 12.73 & & & & \\
\hline Constant & & & & $1.82[0.31,3.32]$ & & & \\
\hline Positive affect & & & & $0.38[0.13,0.63]$ & .22 & 2.97 & .003 \\
\hline Negative affect & & & & $-0.10[-0.28,0.09]$ & -.07 & -1.02 & .309 \\
\hline Dysthymia & & & & $-0.09[-0.42,0.23]$ & -.05 & -0.56 & .573 \\
\hline Euthymia & & & & $0.54[0.23,0.85]$ & .29 & 3.41 & .001 \\
\hline Total $R^{2}$ & $.25^{* * *}$ & & & & & & \\
\hline
\end{tabular}


Table 3

Multiple regression analysis predicting satisfaction with life (SWLS) - model 2: two predictors

\begin{tabular}{lcccc}
\hline Predictor variable & $B[95 \% \mathrm{CI}]$ & $\beta$ & $t$ & $p$ \\
\hline Constant & $1.09[0.36,1.82]$ & & & \\
Positive affect & $0.40[0.16,0.64]$ & .23 & 3.32 & .001 \\
Euthymia & $0.64[0.38,0.90]$ & .34 & 4.85 & $<.001$ \\
\hline
\end{tabular}

Note. $R^{2}=.25, p<.001$; Akaike information criterion $\mathrm{AIC}=-6.40$, Bayesian information criterion $\mathrm{BIC}=3.69$.

\section{DISCUSSION}

The present study was focused on trait depression as a predictor of subjective well-being. Most conceptualizations of depressiveness, including, in particular, those referring to depression as a clinical condition, are focused on the presence of negative experiences. We, however, adopted Spielberger's (e.g., Spielberger et al., 2003) proposition to take into account not only the dysthymic aspect of depression but also its euthymic facet, which refers to the deficits of positive experiences. Such conceptualization of trait depression, as the combination of interrelated dysthymia and euthymia facets, is claimed to be particularly relevant for the non-clinical population since it helps in distinguishing between milder levels of depressiveness (Krohne et al., 2002).

We postulated that for adults from the general population, euthymia is a more important (compared to dysthymia) predictor of subjective well-being as conceptualized in terms of satisfaction with life. Additionally, we expected that this effect would be relatively independent of the basic level of positive and negative affect. The results of our study fully confirmed our expectations. NA served as a statistically significant predictor of life satisfaction only until dysthymia was taken into account. Still, the predictive role of dysthymia remained only until euthymia was entered as a predictor. When all four predictors (PA, NA, dysthymia, and euthymia) were entered in the regression model only those related to positive affectivity (PA and euthymia) served as statistically significant predictors. Though they both contributed independently to the variance of satisfaction with life explained by the model, the predictive role of euthymia was noticeably stronger.

This is in line with the results of several studies which showed associations between diminished positive emotions and elevated depressive symptoms as independent of negative emotions (Feldman et al., 2008; Nelis et al., 2015; Raes et al., 2012; Werner-Seidler et al., 2013). Still, our results suggest that in addition to temperamental level of PA, more specific positive experiences should be considered to adequately address depression-related issues in the non-clinical population. When one adopts the tra- ditional approach to depressiveness focused on the dysthymic aspect only, one may not be able to differentiate between milder levels of this personality disposition, which will result in limited ability of trait depression to predict important outcomes, such as subjective well-being.

Our findings point to a likely attentional mechanism by which emotions promote well-being and alleviate depression, with a stronger effect of euthymia and PA than dysthymia and NA. The experience of positive affect may increase individuals' selective attention preferences for positive information, and this broadened attention towards positive information may facilitate emotion regulation by helping individuals to attend to opportunities for reward in their environment. This is in line with the broaden-and-build theory by Fredrickson (e.g., Cohn et al., 2009; Fredrickson, 2001) claiming that positive emotions broaden thought and action repertoires, increase mental flexibility, augment meaning-based coping, and motivate engagement in novel activities and social relationships. This leads to trying new activities, developing new skills, and engaging in more positive social interactions (Garland et al., 2010; Smith \& Hollinger-Smith, 2015). Presence of positive emotions extends coping resources, leads to better stress management and restores resilience (Dolphin et al., 2015; Folkman, 1997).

The results of the present study have also applicative potential. Many arguments have been made to suggest that mental illness can or even should be treated by promoting well-being strategies, and that positive psychology approaches may be instrumental in order to delay adverse health outcomes (Lamers et al., 2012; Rao et al., 2017). Enhancing positive emotionality is an important treatment goal for persons with lower levels of happiness (Sin \& Lyubomirsky, 2009; Spinhoven et al., 2015). Our findings add to this by pointing out not only the importance of positive interventions but also the need for monitoring the level of state euthymia in the prevention programmes against depression. Decreased state euthymia may serve as a warning signal of an incoming depression episode, which may be detectable before more severe symptoms appear. Preparing for the presence of euthymia, on the other hand, may 
enhance subjective well-being, which, in light of our study, seems to be more important than dealing with negative emotions. Still, to verify the effectiveness of such preventive programmes future applied studies are needed, assessing and controlling not only the trait but also the state aspect of euthymia.

Although recruiting the sample from communitydwelling adults was fully consistent with the purpose of this particular study, one may wonder if the pattern of results would be different for those who are clinically depressed. Indeed, the results of our other study suggest that this may be the case. For clinically depressed participants dysthymia seemed to be at least as important as euthymia in predicting SWB (Łysiak \& Bąk, 2018). Unfortunately, since it was not the main objective of that study, we used very simplified, one-item measures of SWB, which made it difficult to adequately test the above hypothesis. Thus, further studies are needed to directly test the independent role of dysthymia and euthymia in predicting SWB in clinical as compared to non-clinical samples. Moreover, given that all the measures used in the present study were self-report inventories, it would be beneficial in future studies to go beyond self-report and include e.g. physicians' ratings of symptoms of depression.

Another limitation is the cross-sectional design of our study, which does not allow any cause and effect inferences to be made. We tested the regression model with trait depression as a predictor of SWB, but we are aware that this in fact may be a bidirectional relationship. To explicitly test the hypothesis that euthymia is one of the important causes or mechanisms of satisfaction with life, a longitudinal design would be optimal.

\section{ACKNOWLEDGEMENTS}

The data that support the findings of this study are openly available in the Open Science Framework repository at http://doi.org/10.17605/OSF.IO/WDEZB.

\section{References}

Allen, M. S., Magee, C. A., \& Vella, S. A. (2016). Personality, hedonic balance and the quality and quantity of sleep in adulthood. Psychology \& Health, 31, 1091-1107. https://doi.org/10.1080/08870446.2016. 1178745

Bąk, W., \& Łysiak, M. (2018, July 17-21). Measurement of depressive emotions in non-clinical samples. Polish adaptation of STDS [Poster presentation]. 19th European Conference on Personality, Zadar, Croatia.

Bąk, W., \& Oleś, P. K. (2005). Polish adaptation of the State-Trait Depression Scales [Unpublished manu- script]. Institute of Psychology, Catholic University of Lublin, Poland.

Brzozowski, P. (2010). Skala uczuć pozytywnych i negatywnych SUPIN. Polska adaptacja skali PANAS Davida Watsona i Lee Anny Clark [SUPIN - positive and negative affect scale. Polish adaptation of PANAS by David Watson and Lee Anna Clark]. Psychological Test Laboratory of the Polish Psychological Association.

Caprara, G. V., \& Steca, P. (2006). The contribution of self-regulatory efficacy beliefs in managing affect and family relationships to positive thinking and hedonic balance. Journal of Social and Clinical Psychology, 25, 603-627. https://doi.org/10.1521/ jscp.2006.25.6.603

Carandang, R. R., Shibanuma, A., Kiriya, J., Asis, E., Chavez, D. C., Meana, M., Murayama, H., \& Jimba, M. (2019). Determinants of depressive symptoms in Filipino senior citizens of the communitybased ENGAGE study. Archives of Gerontology and Geriatrics, 82, 186-191. https://doi.org/10.1016/j. archger.2019.02.014

Cattell, R. B., \& Scheier, I. H. (1960). Stimuli related to stress, neuroticism, excitation, and anxiety response patterns: Illustrating a new multivariate experimental design. Journal of Abnormal and Social Psychology, 60, 195-204. https://doi.org/10.1037/ h0046347

Cohn, M. A., Fredrickson, B. L., Brown, S. L., Mikels, J. A., \& Conway, A. M. (2009). Happiness unpacked: Positive emotions increase life satisfaction by building resilience. Emotion, 9, 361-368. https://doi.org/10.1037/a0015952

Derdikman-Eiron, R., Indredavik, M. S., Bratberg, G. H., Taraldsen, G., Bakken, I. J., \& Colton, M. (2011). Gender differences in subjective well-being, self-esteem and psychosocial functioning in adolescents with symptoms of anxiety and depression: Findings from the Nord-Trøndelag health study. Scandinavian Journal of Psychology, 52, 261-267. https://doi. org/10.1111/j.1467-9450.2010.00859.x

Diener, E. (1984). Subjective well-being. Psychological Bulletin, 95, 542-575. https://doi.org/10.1037/00332909.95.3.542

Diener, E., Emmons, R. A., Larsen, R. J., \& Griffin, S. (1985). The Satisfaction with Life Scale. Journal of Personality Assessment, 49, 71-75. https://doi.org/ 10.1207/s15327752jpa4901_13

Dolphin, K. E., Steinhardt, M. A., \& Cance, J. D. (2015). The role of positive emotions in reducing depressive symptoms among army wives. Military Psychology, 27, 22-35. https://doi.org/10.1037/ mil0000062

Fava, G. A., \& Bech, P. (2016). The concept of euthymia. Psychotherapy and Psychosomatics, 85, 1-5. https://doi.org/10.1159/000441244

Feldman, G. C., Joormann, J., \& Johnson, S. L. (2008). Responses to positive affect: a self report measure 
of rumination and dampening. Cognitive Therapy and Research, 32, 507-525. https://doi.org/10.1007/ s10608-006-9083-0

Folkman, S. (1997). Positive psychological states and coping with severe stress. Social Science \& Medicine, 45, 1207-1221. https://doi.org/10.1016/S02779536(97)00040-3

Fredrickson, B. L. (2001). The role of positive emotions in positive psychology. The broaden-and-build theory of positive emotions. American Psychologist, 56, 218-226. https://doi.org/10.1037/0003-066X.56. 3.218

Gargiulo, R. A., \& Stokes, M. A. (2009). Subjective well-being as an indicator for clinical depression. Social Indicators Research, 92, 517-527. https://doi. org/10.1007/s11205-008-9301-0

Garland, E. L., Fredrickson, B., Kring, A. M., Johnson, D. P., Meyer, P. S., \& Penn, D. L. (2010). Upward spirals of positive emotions counter downward spirals of negativity: Insights from the broaden-and-build theory and affective neuroscience on the treatment of emotion dysfunctions and deficits in psychopathology. Clinical Psychology Review, 30, 849-864. https://doi.org/10.1016/j. cpr.2010.03.002

Goldberg, J. F., \& Harrow, M. (2005). Subjective life satisfaction and objective functional outcome in bipolar and unipolar mood disorders: a longitudinal analysis. Journal of Affective Disorders, 89, 79-89. https://doi.org/10.1016/j.jad.2005.08.008

Juczyński, Z. (2012). Narzędzia pomiaru w promocji i psychologii zdrowia [Measurement tools in health promotion and psychology]. Psychological Test Laboratory of the Polish Psychological Association.

Krohne, H. W., Schmukle, S. C., Spaderna, H., \& Spielberger, C. D. (2002). The state-trait depression scales: an international comparison. Anxiety, Stress and Coping, 15, 105-122. https://doi. org/10.1080/10615800290028422

Lamers, S. M. A., Bolier, L., Westerhof, G. J., Smit, F., \& Bohlmeijer, E. T. (2012). The impact of emotional well-being on long-term recovery and survival in physical illness: a meta-analysis. Journal of Behavioral Medicine, 35, 538-547. https://doi. org/10.1007/s10865-011-9379-8

Łysiak, M., \& Bąk, W. (2018, July 2-4). Eutymia vs dystymia a jakość życia. Badania populacji klinicznej $i$ zdrowej [Euthymia vs. dysthymia and the quality of life. Study on the clinical and healthy samples]. Paper presented at the Third Conference of Positive Psychology, Warsaw, Poland.

McCrae, R. R., \& Costa, P. T. (2003). Personality in adulthood: a five-factor theory perspective. $2^{\text {nd }}$ ed. Guilford Press.

Nelis, S., Holmes, E. A., \& Raes, F. (2015). Response styles to positive affect and depression: Concurrent and prospective associations in a community sam- ple. Cognitive Therapy and Research, 39, 480-491. https://doi.org/10.1007/s10608-015-9671-y

Nezlek, J. B. (2007). A multilevel framework for understanding relationships among traits, states, situations and behaviours. European Journal of Personality, 21, 789-810. https://doi.org/10.1002/per.640

Raes, F., Schoofs, H., Griffith, J. W., \& Hermans, D. (2012). Rumination relates to reduced autobiographical memory specificity in formerly depressed patients following a self-discrepancy challenge: The case of autobiographical memory specificity reactivity. Journal of Behavior Therapy and Experimental Psychiatry, 43, 1002-1007. https:// doi.org/10.1016/j.jbtep.2012.03.003

Rao, S. K., Wallace, L. M. K., Theou, O., \& Rockwood, K. (2017). Is it better to be happy or not depressed? Depression mediates the effect of psychological well-being on adverse health outcomes in older adults. International Journal of Geriatric Psychiatry, 32, 1000-1008. https://doi.org/10.1002/gps.4559

Ryan, R. M., \& Deci, E. L. (2001). On happiness and human potentials: a review of research on hedonic and eudaimonic well-being. Annual Review of Psychology, 52, 141-166. https://doi.org/10.1146/annurev.psych.52.1.141

Schimmack, U. (2003). Affect measurement in experience sampling research. Journal of Happiness Studies, 4, 79-106. https://doi.org/10.1023/A:102366 1322862

Sin, N. L., \& Lyubomirsky, S. (2009). Enhancing wellbeing and alleviating depressive symptoms with positive psychology interventions: a practicefriendly meta-analysis. Journal of Clinical Psychology, 65, 467-487. https://doi.org/10.1002/jclp.20593

Smith, J. L., \& Hollinger-Smith, L. (2015). Savoring, resilience, and psychological well-being in older adults. Aging \& Mental Health, 19, 192-200. https:// doi.org/10.1080/13607863.2014.986647

Spielberger, C. D. (2006). Cross-cultural assessment of emotional states and personality traits. European Psychologist, 11, 297-303. https://doi.org/ 10.1027/1016-9040.11.4.297

Spielberger, C. D., \& Reheiser, E. C. (2009). Assessment of emotions: Anxiety, anger, depression, and curiosity. Applied Psychology: Health and WellBeing, 1, 271-302. https://doi.org/10.1111/j.17580854.2009.01017.x

Spielberger, C. D., Ritterband, L. M., Reheiser, E. C., \& Brunner, T. M. (2003). The nature and measurement of depression. International Journal of Clinical and Health Psychology, 3, 209-234. https://doi. org/10.1007/978-0-387-89676-2_23

Spinhoven, P., Elzinga, B. M., Giltay, E., \& Penninx, B. W. J. H. (2015). Anxious or depressed and still happy? PLoS One, 10, 1-17. https://doi. org/10.1371/journal.pone.0139912

Stillmaker, J., \& Kasser, T. (2013). Instruction in problem-solving skills increases the hedonic balance 
of highly neurotic individuals. Cognitive Therapy and Research, 37, 380-382. https://doi.org/10.1007/ s10608-012-9466-3

Van Beveren, M. L., Harding, K., Beyers, W., \& Braet, C. (2018). Don't worry, be happy: The role of positive emotionality and adaptive emotion regulation strategies for youth depressive symptoms. British Journal of Clinical Psychology, 57, 18-41. https://doi. org/10.1111/bjc. 12151

Watson, D., Clark, L. A., \& Tellegen, A. (1988). Development and validation of brief measures of positive and negative affect:The PANAS scales. Journal of Personality and Social Psychology, 54, 10631070. https://doi.org/10.1037/0022-3514.54.6.1063

Watson, D., \& Tellegen, A. (1985). Toward a consensual structure of mood. Psychological Bulletin, 98, 219-235. https://doi.org/10.1037/0033-2909.98.2.219

Werner-Seidler, A., Banks, R., Dunn, B. D., \& Moulds, M. L. (2013). An investigation of the relationship between positive affect regulation and depression. Behaviour Research and Therapy, 51, 46-56. https://doi.org/10.1016/j.brat.2012.11.001

Wood, A. M., \& Joseph, S. (2010). The absence of positive psychological (eudemonic) well-being as a risk factor for depression: a ten year cohort study. Journal of Affective Disorders, 122, 213-217. https://doi.org/10.1016/j.jad.2009.06.032

Xu, Y., Yu, Y., Xie, Y., Peng, L., Liu, B., Xie, J., Bian, C., $\& \mathrm{Li}, \mathrm{M}$. (2015). Positive affect promotes well-being and alleviates depression: The mediating effect of attentional bias. Psychiatry Research, 228, 482-487. https://doi.org/10.1016/j.psychres.2015.06.011 